\title{
Survey on Energy Drink Consumption Among the Adult Population in Sicily: Do New Drinking Habits Associate with the Risk of Alcoholism in the Crib of Mediterranean Diet?
}

\author{
Alessandra Casuccio, ${ }^{1,}$ Palmira Immordino, ${ }^{1}$ Rossella Falcone, ${ }^{1}$ Fanny Pojero, ${ }^{1}$ and Sara Palmeri ${ }^{1}$ \\ ${ }^{1}$ Department of Sciences for Health Promotion and Mother-Child Care “G. D’Alessandro" University of Palermo, Italy \\ "Corresponding author: Alessandra Casuccio, Via del Vespro 133, 90127, Palermo, Italy. Tel: +39-916553613, Fax: +39-916553641, E-mail: alessandra.casuccio@unipa.it
}

Received 2016 March 21; Revised 2016 October 09; Accepted 2016 November 29.

\begin{abstract}
Background: The market for and the level of energy drinks (EDs) consumption are increasing every year, and while only a few have a comprehensive knowledge about the potential harmful physiological and psychological effects of EDs, the number of publications that have documented the potential adverse risks associated with the use of these beverages remains small.

Objectives: The present study aim to evaluate the prevalence of EDs consumers among the adult population and to verify the factors associated with its consumption and onset of adverse events.

Patients and Methods: A cross-sectional survey was conducted using a knowledge, attitudes, and practices (KAP) semi-structured questionnaire, administered to adult population of central Sicily, Italy.

Results: In this study, 217 adults were interviewed. Of the respondents, 77.9\% were current EDs consumers. A significant difference was observed in the level of education $(\mathrm{P}=0.022)$, with particular preponderance of ED-drinking individuals among those with middle school education compared to those with higher education levels, and with a habit of consuming alcohol more frequently than nonusers $(\mathrm{P}=0.031)$. For $73 \%$ of the respondents, ED consumption was associated with consumption of alcohol, and $21 \%$ of the interviewed participants stated they had suffered from disorders caused by drinking EDs. With regards to differences between sexes, males had drunk EDs for a longer period than females (OR 1.74 (1.15 - 2.97); $\mathrm{P}=0.041)$. The predominant motivation was sports for males (OR 6.5 (1.88 - 22.48); $\mathrm{P}=0.003)$, and studying for females (OR 4.25 (1.25 - 14.4); $\mathrm{P}=0.020)$. The females also claimed to drink EDs particularly on weekends and to have suffered more symptoms than males (OR 2.429 (1.14 - 5.18), $\mathrm{P}=0.021$ ).

Conclusions: The results of this study confirm a large use of EDs among the adult population and the side effects reported may represent a health risk. The use of EDs may influence ingestion of large amount of alcohol. This result indicates the need for a thorough evaluation of this social phenomenon.
\end{abstract}

Keywords: Adult, Alcoholism, Energy Drink, Risky Behavior

\section{Background}

Energy drinks (EDs) are non-alcoholic beverages marketed as improving energy, alertness, concentration, and athletic performance due to the presence of high doses of stimulants, mainly caffeine, taurine, glucuronolactone, carnitine, and a combination of other ingredients (such as guarana, ginseng, and vitamins among others) (1). Most EDs contain enormous quantities of sugar (up to a quarter of a cup per can); the sugar-free version contains aspartame and acesulfame $\mathrm{K}$ in place of sugar.

While often consumed by athletes in the hope of improving performance, consumption of energy drinks is on the rise in the general population, particularly among adolescents and young adults $(2,3)$. Marketing campaigns focused on improving performance, attention, and strength are, in fact, aimed mainly at these 2 age groups, and this can increase the risk of caffeine intoxication from energy drink consumption (4).

The energy drink industry is booming, with sales estimated to be over 12.5 billion USD in 2012, an increase of $60 \%$ from 2008 to $2012(5,6)$. In Italy, ED consumption rose from 2.67 million litres in 2006 to 2.97 million litres in 2009 (an increase of $11 \%$ ), registering a prevalence rate of $28 \%$ in the adult population (6). In 2011, the European Food Safety Authority (EFSA) commissioned a study to gather data on the consumption of energy drinks in 16 countries of the European Union. The report revealed that $68 \%$ of the adolescents (aged $10-18$ years), 30\% of adults, and $18 \%$ of children ( $<10$ years old) consumed energy drinks (6).

However, the excessive consumption of EDs is not considered free from risk to human health. The possible adverse effects of this habit were associated with particularly high caffeine content (>300 mg/day) and the fact that EDs facilitate contingent alcohol consumption. Caffeine content can vary from about 50 to $500 \mathrm{mg}$; the caffeine content 
of an ED can be $150 \%-300 \%$ higher than that of a common Cola (7).

Moreover, moderate intake of caffeine was associated with an improvement in many aspects of cognitive performance such as level of attention, reaction time, memory, and psychomotor reactivity among others; on the other hand, abuse of caffeine has been linked to the onset of symptoms and signs of poisoning such as nausea / vomiting, tachycardia, hypertension, agitation, tremor, dizziness, and chest pain $(8,9)$. Scientific literature presents several reports on the harmful effects of energy drinks (10-15). The evidence put forth clearly suggests that there are some serious gaps in physiology education among teenagers, parents, and the society.

The stimulating effect of caffeine and other substances also seems to be able to mask the depressant effects of alcohol, so that the consumers may underestimate their level of alcoholic intoxication (16), or even increase their alcohol consumption, exposing themselves to an augmented risk of alcohol dependence (8).

There are several articles about the consumption of EDs in the literature, especially among the student population or adolescents $(1,17-22)$, while there is a paucity of studies on the adult population. The phenomenon may assume an important dimension in countries characterized by a large diffusion of the Mediterranean Diet, especially in Sicily, where a significant deviation from the Mediterranean dietary habits (and associated health benefits) among adolescents, younger, and less educated people has been well documented $(23,24)$.

\section{Objectives}

The present study aim to evaluate the frequency of ED consumers among the adult population in Sicily, Italy. More specifically, we aim to examine the extent of the phenomenon in more rural areas, where the influence of Mediterranean Diet is supposed to be well preserved compared to larger towns (24). Moreover, we verified the possible factors associated with type of consumption and the possibility of onset of adverse events and alcoholism.

\section{Patients and Methods}

\subsection{Setting and Population Study}

This survey was performed on the adult population of Milena, a small town in central Sicily, Italy, located in a mountainous area 423 meters above thesea level, with 3119 inhabitants. Of the city residents, $13.2 \%$ were under 18 years, $10.4 \% 18$ to 24 years, $5.1 \% 25$ to 29 years, $17.4 \% 30$ to 45 years, $29.6 \% 46$ to 65 years, and $24.3 \%$ over 65 years of age.
With regards to socioeconomic conditions, the Milena area is dedicated to farming, almost entirely wheat, but also vineyards, almonds, beans, and tomatoes. Most of the population is engaged in agriculture or related industries, but there is also a small handmade iron and wood manufacturing sector.

\subsection{Survey Instrument}

The survey was conducted for one week from November 1 to November 7, 2014, in 2 main bars in Milena, which were open from $7 \mathrm{am}$ to $2 \mathrm{am}$, where most of the population came for breakfast and for beverages like tea, coffee, or fruit juice, or spent their evening with friends. To avoid selection bias, which could affect the result and cause the exclusion of potentially relevant subgroups, we included all the customers aged $\geq 18$ years in the survey.

To evaluate knowledge, attitudes and consumption practices regarding EDs, a K.A.P.(Knowledge, Attitudes, and Practices) semi-structured questionnaire in Italian containing 24 items was administered by 2 trained interviewers to individuals aged 18 or older immediately after obtaining their written informed consent (supplementary file). The questionnaire was designed by the author and has been used previously in a recent paper by the authors (17). Questions 1 to 9 were about demographical data and lifestyle (consumption of alcoholic beverages, coffee, and smoking cigarettes); questions 10 to 12 assessed knowledge of EDs, the stimulant substances they contain, and their effects; questions 13 and 14 were used to identify ED consumers (attitudes towards EDs), and if participants responded by "no", then they were instructed to go to question number 21. Participants who responded "yes" to Question 14 were instructed to continue the survey, which assessed the following: the type of energy drink usually consumed (regular or sugar-free); and situations for which energy drinks were used (doing sports, studying, at parties). Questions 15 to 18 identified practices and expectations on the use of EDs such as ED consumption per month ("How often do you drink energy drinks?" and "How many cans do you usually drink?"), and ED consumption alone or in association with alcoholic beverages. Questions 19 to 20 asked about the side effects associated with ED use (headache, insomnia, tremors, palpitations, nervousness, and anxiety). Questions 21 to 23 were addressed to nonusers to discover the reasons why they do not usually use EDs and the presence of any ED-related side effects in the past.

The study was performed in accordance with the principles of the Declaration of Helsinki, and the study protocol was approved by the ethics committee of the Azienda Ospedaliero-Universitaria Policlinico "P. Giaccone" in Palermo, Italy. 


\subsection{Statistical Analysis}

Statistical analysis of the quantitative and qualitative data including descriptive statistics was performed for all the items. Frequency analysis was performed with chisquare test and Fisher's exact test as needed. The one-way analysis of variance (ANOVA) and Mann-Whitney U statistic test were used for parametric and nonparametric analysis, respectively. We used logistic regression analysis to examine the cross-sectional associations between demographic characteristics and behavioural habits in energy drink consumption. Data were analysed by IBM SPSS Software Version 22 (IBM Corp., Armonk, NY, USA). All P values were 2sided and $\mathrm{p}<0.05$ was considered statistically significant.

\section{Results}

\subsection{Demographic Characteristics and Habits of Overall Popula-} tion

By the end of the study, 217 respondents, whose demographic characteristics are reported in Table 1, had filled out 217 questionnaires. Of the respondents, 137 (63.1\%) were male and 80 (36.9\%) were female. The average age of the sample was 28.7 years ( $S D \pm 8.1$, range 18 - 60). As for educational qualifications, $60 \%$ had a diploma, while middle school and university graduates were equally distributed. Regarding the main professional activity, $37 \%$ were graduate or postgraduate students, about $22 \%$ were not permanently employed, and others were employees or farmers. Moreover, of the respondents, $57 \%$ were smokers, with no significant differences between the sexes and in the number of cigarettes smoked; 75\% were regular coffee drinkers, with no differences between sexes. The overall frequency of alcohol consumption was $83 \%$, almost the same for both sexes.

\subsection{Knowledge of EDs}

With respect to knowledge of EDs (Table 2), between $70 \%$ and $90 \%$ of the respondents declared that they knew the main constituents of EDs (caffeine, taurine, and sugar), while between $7 \%$ and $20 \%$ of the respondents knew the less possible constituents (vitamins, glucuronolactone, sweeteners, aspartame, carnitine, and guarana). On the other hand, proper knowledge of the physiological effects (especially the effects on metabolism and concentration) was not as high: about 50\% to 60\% knew that EDs generally help stay awake.

\subsection{Attitudes Towards EDs}

All the respondents (current users and non-users) reported having consumed EDs in the past. Of the participants, 169 (77.9\%) stated that they currently consumed EDs

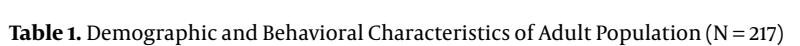

\begin{tabular}{|c|c|c|}
\hline Variables & No. & $\%$ \\
\hline \multicolumn{3}{|l|}{ Age groups, $y$} \\
\hline $18-24$ & 64 & 29.5 \\
\hline $25-30$ & 78 & 35.9 \\
\hline $30-35$ & 47 & 21.7 \\
\hline$>35$ & 28 & 12.9 \\
\hline \multicolumn{3}{|l|}{ Gender } \\
\hline Female & 80 & 36.9 \\
\hline Male & 137 & 63.1 \\
\hline \multicolumn{3}{|l|}{ Educational level } \\
\hline Middle school graduates & 44 & 20.3 \\
\hline High school graduates & 131 & 60.4 \\
\hline University graduates & 42 & 19.4 \\
\hline \multicolumn{3}{|l|}{ Main professional activity } \\
\hline Graduate and post graduate student & 80 & 36.9 \\
\hline Tradesman/Executive & 16 & 7.4 \\
\hline Unemployed & 47 & 21.7 \\
\hline Employee & 41 & 18.9 \\
\hline Workman & 33 & 15.2 \\
\hline \multicolumn{3}{|l|}{ Body Mass Index (BMI) ${ }^{a}$} \\
\hline Underweight & 7 & 3.2 \\
\hline Normal & 144 & 66.4 \\
\hline Overweight & 57 & 26.3 \\
\hline Obese & 9 & 4.1 \\
\hline Smoking habits & 124 & 57.1 \\
\hline Habit of coffee drinking & 162 & 74.7 \\
\hline Habit of alcohol drinking & 181 & 83.4 \\
\hline
\end{tabular}

(Table 2). Almost all respondents (92.3\%) consumed the sugared version. The comparison between ED consumers (169, $77.9 \%$ ) vs. current nonusers $(48,22.1 \%$ ) (Table 3 ) did not show any significant differences in gender, age, BMI, occupation, smoking, and drinking coffee, while there was a significant difference in the level of education $(\mathrm{P}=0.022)$, with a particular preponderance of ED-drinking individuals with a middle school education compared to a higher qualification, and with the habit of consuming alcohol more frequently than nonusers $(\mathrm{P}=0.031)$. Among the 48 respondents who did not currently consume EDs, 28 (58\%) stated that they did not drink them because they did not like these drinks, $23 \%$ did not drink them for fear of suf- 
Table 2. Knowledge, Attitudes and Practices (KAP) Regarding EDs Consumption by Adult Population ${ }^{\mathrm{a}}$

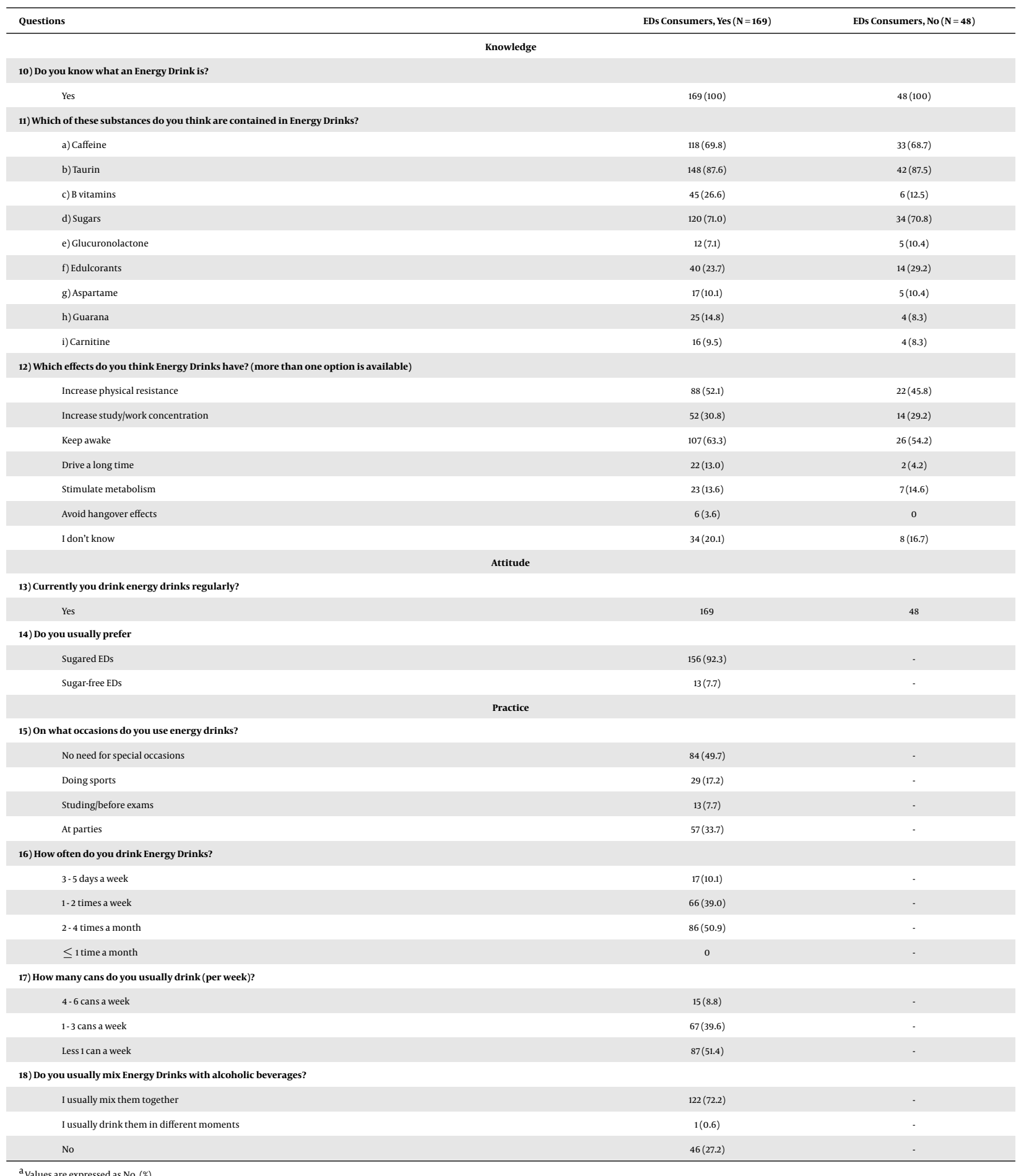


fering disorders, and about 15\% said they do not drink energy drinks because they cause ailments including insomnia and palpitations.

\subsection{ED Consumption Practices}

Among the 169 respondents who stated that they used EDs regularly, 78.1\% had consumed them for more than 3 years; $50 \%$ said they consumed them mostly without a reason, 34\% claimed to consume them for enjoyment, $17 \%$ for sports, and around $8 \%$ for studying (Table 2 ); $10 \%$ of the consumers said they drank EDs 3 to 5 times a week, $39 \% 1$ to 2 times a week, and 50\% less than once a week. Moreover, $39 \%$ consumed 1 to 3 cans a week, $8 \%$ between 4 to 6 cans, and $50 \%$ less than 1 can a week. For $72 \%$ of the participants, ED consumption was combined with the consumption of alcohol, and in all cases, they were mixed in the same glass; $21 \%$ (35 consumers) said they have suffered disorders as a result of drinking EDs including nervousness (46\%), palpitations (43\%), insomnia (37\%), tremor (34\%), headache (20\%), or anxiety (17\%). Of the participants, $37 \%$, who reported experiencing symptoms, had experienced one symptom only, 31\% two symptoms, $26 \%$ three symptoms, and $6 \%$ four symptoms at the same time. There was no significant difference between the sexes in alcohol consumption habits although mode of consumption was different, with females more likely to drink alcohol on weekends and males drinking on a daily basis $(\mathrm{P}<0.0005)$.

With respect to the differences in ED consumption between the sexes, males had drunk EDs for a longer period than females (OR 1.74 (1.15 - 2.97); $\mathrm{P}=0.041)$. The predominant motivation was sports for males (OR 6.5 (1.88 - 22.48); $\mathrm{P}=0.003$ ), and studying for females (OR 4.25 (1.25 - 14.4); $\mathrm{P}$ $=0.020)$. Moreover, females also claimed to have suffered more symptoms after drinking EDs than males (OR 2.429 (1.14 - 5.18), $\mathrm{P}=0.021)$.

\section{Discussion}

Our report was one of the first to dissect deep knowledge, attitude, and practices regarding energy drink consumption, prevalence rate, and frequency of use as well as prevalence of its adverse side effects among the adult population, giving that most Italian and international studies have been conducted among adolescents and college students $(1,17-22,25,26)$. Our results completed and expanded those already published in 2014 on energy drink consumption and prevalence of its side effects among medical students (17).

Comparing the results of the current study with European data for the adult population, collected in a large work published in 2011 by EFSA (European food safety authority) (6), we found that the prevalence of ED consumption was considerably higher in our sample. In fact, in our study, $78 \%$ of the participants currently consumed EDs, while around $30 \%$ of the total respondents in the EFSA study ( $28 \%$ of the Italians) declared to have consumed EDs at least once in the previous year (21\% of the total consumers in the EFSA study claimed to drink EDs once a week, versus $49 \%$ in our study.). In line with the EFSA study, in which around $71 \%$ of ED consumers were in the 18 to 29 age group, our results confirm that EDs are highly popular among the general population, particularly among young people. In fact, $43 \%$ of our ED consumers aged 18 to 24 years, $34 \% 25$ to 29 , and others (22\%) were over 30 years of age. This result was confirmed by other studies conducted in open populations (27-29). Moreover, our precedent study on medical students' habits revealed that ED consumption decreased with age, with ED consumers being younger $(P=0.027)$ than nonusers $(17)$. Moreover, our analysis revealed that consumption of EDs was significantly related to education level; it was especially prevalent among those participants with middle school education level rather than those more educated, widening our precedent report indicating that among medical students only $22 \%$ of respondents, particularly males ( $\mathrm{P} \leq 0.0005)$, were regular consumers (17). Conversely, most of the respondents in the EFSA study declared to have completed upper secondary school (39\%) or to have a university degree (29\%) (6). These data collocate in a complex frame characterized by a shift in alimentary habits in Sicily toward a more elaborated and less healthy dietary regimen far from the traditional Mediterranean Diet evident just in younger adults and those with low education levels (30). This suggests that an intriguing and potentially health damaging change in the life style of the new generations is happening, which necessitates paying attention to and monitoring the evolution of the situation at regional level. Thus, conducting further studies that also consider other variables (for, example; nutrition assessment) is highly recommended.

In our study, no differences were found in ED consumption between the sexes, as in the EFSA study (6); however, a large Australian study based on telephone interviews with 2000 individuals revealed that overall prevalence of ED consumption was $13.4 \%$, with a clear majority of male consumers (17.75\%) over females (6\%) (27). However, in our study, males seem to have consumed EDs for a longer time than females. Also, the main reasons for consumption were different, with sports being the main motivation for males and studying for females. An American survey conducted among college students found that motivation for consuming energy drinks was the same for both males and 
Table 3. Characteristics on Consumption of Energy Drinks in Adult Population

\begin{tabular}{|c|c|c|c|}
\hline Characteristics & EDs Consumers, Yes $(N=169)$ & EDs Consumers, $\mathrm{No}(\mathrm{N}=48)$ & P Value \\
\hline Age, y; mean (SD) & $26.5(6.3)$ & $29(9.0)$ & 0.073 \\
\hline Body Mass Index (BMI), No. (\%) & & & 0.095 \\
\hline Underweight & $7(4.1)$ & $0(0)$ & \\
\hline Normal & $116(68.6)$ & $28(58.3)$ & \\
\hline Obese & $5(3.0)$ & $4(8.4)$ & \\
\hline Gender (F/M), No. (\%) & $63 / 106(37.3 / 62.7)$ & $17 / 31(35.4 / 64.6)$ & 0.867 \\
\hline Educational level, No(\%) & & & 0.022 \\
\hline Middle school graduates & $41(24.3)$ & $3(6.3)$ & \\
\hline High school graduates & $96(56.8)$ & $35(72.9)$ & \\
\hline University graduates & $32(18.9)$ & $10(20.8)$ & \\
\hline Smoking habit $(\mathrm{Y} / \mathrm{N})$ & $94 / 75(55.6 / 44.4)$ & $30 / 18(62.5 / 37.5)$ & 0.414 \\
\hline Habit of coffee drinking $(\mathrm{Y} / \mathrm{N})$ & $123 / 46(72.8 / 27.2)$ & $39 / 9(81.3 / 18.7)$ & 0.264 \\
\hline Habit of alcohol drinking $(\mathrm{Y} / \mathrm{N})$ & $146 / 23(86.4 / 13.6)$ & $35 / 13(72.9 / 27.1)$ & 0.031 \\
\hline
\end{tabular}

females and regarded insufficient sleep and the need for more energy in general; studying and driving a car for long periods of time prevailed for males, while the habit of mixing them with alcohol at parties prevailed for women (31).

The EFSA updates revealed that around 56\% of ED consumers (58\% of Italian ED consumers) declared that they consumed ED and alcohol together (6), with no gender differences in ED consumption habits, but as for alcohol consumption, only $14 \%$ of females declared that they consumed ED and alcohol compared to $21 \%$ of the males. Another study published in 2010 measured athletes' alcohol and energy drink consumption and their combined use and found that of the total sample of 401 intercollegiate student-athletes, 78\% used alcohol and 37\% combined alcohol with energy drinks (32). In our precedent study, we documented that among medical students, ED consumers drank alcohol more frequently $(\mathrm{P}=0.008)$ than nonusers, and 51\% consumed alcohol in combination with EDs, with a highly significant difference $(\mathrm{P}<0.0005)$ between males mixing alcohol and EDs (63\%) and female consumers (28\%) (17). Similarly, Oteri et al. (19) found that $48.4 \%$ of college students at the University of Messina, Italy, mixed energy drinks with alcohol. The data included in our survey demonstrated a high positive association between the use of energy drinks and alcohol consumption (73\% of all ED consumers), especially among youths, with no significant difference between the sexes with respect to the habit of consuming alcohol although females were more likely to on weekends and males were more prone to consume EDs daily. This piece of information may be extremely impor- tant in planning targeted formative intervention strategies to prevent the risk of excessive alcohol ingestion associated with ED consumption.

Some studies have shown that the association of EDs with alcohol can increase the risk of binge drinking as a result of a high intake of caffeine, which reduces awareness of the amount of alcohol consumed and perception of alcohol intoxication $(33,34)$. Caffeine can also counteract the depressive effects of alcohol and increase alertness, facilitating the consumption of larger quantities of alcohol (8). The effects of the caffeine-alcohol mixture may also expose the consumer to an increased risk of accidents, risk behaviour, and alcohol dependence (8). This practice includes drinking alcoholic cocktails containing energy drinks, premixed caffeinated alcoholic beverages, or alcohol and EDs drunk separately but within the same drinking occasion (31, 35-37).

In November 2012, the US Food and Drug Administration conducted a research based on reports of significant injuries or deaths associated with energy drinks (13). The reports and data revealed that adverse events ranged from non-serious (e.g., nausea, vomiting, anxiety, and flushing) to significant or serious (e.g., renal failure, seizures, arrhythmias, or death) $(11,12)$. In 2013, the Substance Abuse and Mental Health Services Administration (SAMHSA) published a study on access to emergency care for illnesses caused by energy drinks: the number of visits involving energy drink consumption doubled from 10,068 visits in 2007 to 20783 visits in 2011 (18). Moreover, in 2011, 58\% of the visits were related to consumption of energy drinks 
only, compared to $42 \%$ involving consumption in combination with other drugs (18). In our study, $21 \%$ of the consumers said that they had suffered disorders after consuming EDs. In particular, $46 \%$ had experienced nervousness, $43 \%$ palpitations, 37\% insomnia, 34\% tremor, $20 \%$ headache, and $17 \%$ anxiety; these disorders prevailed in females. The results were lower than those emerged from our previous study on medical students (17) with disorders, in which $45 \%$ declared experiencing side effects after ED consumption, without a statistically significant gender difference.

All these side effects should be seen in the light of the ingestion of main ED components: caffeine, taurine and glucuronolactone. Caffeine is the most widely used psychoactive drug or psychotropic substance in the world, stimulating the nervous system, increasing heart rate and blood pressure, and improving resistance during exercise (38). Doses lower than $500 \mathrm{mg}$ per day result in increased alertness, increase in the speed of speech, decreased sense of fatigue, and decreased sleep. Caffeine is often added to analgesics and painkillers as it increases their pharmacological properties and facilitates absorption (39).

Taurine plays an essential role in maintaining cellular homeostasis. It is normally present in human bile and is involved in many processes that comprise the transmission of nerve impulses and the development of the brain and retina; it fights depression and insomnia, lowers blood pressure, and reduces feelings of fatigue and tiredness (39).

Glucuronolactone is another sugar that is widely used in energy drinks due to its alleged beneficial effects (detoxification and antidepressant properties and improved physical and mental performance) (39).

In adult population, we choose our study targets among regular clients of 2 bars to adapt the survey to those who may be true (alcoholic/non-alcoholic) drinkers and ED consumers rather than general population, who may include individuals less sensitive to commercial campaigns and new trends/fashions). We noticed that the selected sample included mostly young individuals $(65 \%<$ 30 years), not only because they are the main consumers of EDs, but also they represent the age band more interested by changes in dietary habits (30). Our data, thus, reflects the importance of a capillary formative approach directed to new adult generation, who are more exposed to health damages arising from increased alcohol consumption and loss of Mediterranean Dietary alimentary plans. The major limitation of this study was small sample size,. Moreover, the results of the cross-sectional data were based on the responses to self-administered questionnaires, raising the possibility of reporting error and/or social-desirability bias.
The impact of the rise in the popularity of EDs has still not been clearly quantified, but aggressive marketing campaigns aimed at targeting young people in a poorly regulated context have created the conditions for energy drinks to pose a serious threat to public health $(4,40)$. Many studies have shown a close relationship between the excessive use of energy drinks and risky behavior $(14,15$, 41-44). Miller found that common behaviour problems among college students were closely associated with the consumption of EDs (45).

To date, no balanced European legislation has been enacted on defining EDs or regulating them as a separate product class across the 28 European Union (EU) members. Manufacturers are committed to indicating the correct caffeine content, where it is in excess of $150 \mathrm{mg} / \mathrm{L}$ (46). The scope for claims on the benefits of EDs is also significantly restricted. Since December 2012, only the so-called "bodily function" claims, which have been scientifically substantiated and approved by the European commission, may be used (46). Significantly, no claims regarding caffeine or amino acids are currently on the positive list, therefore, such claims are not permitted.

Regulation n.1169/2011 of the European Parliament and the Council on the provision of food information to consumers established that from 14 December 2014 all high caffeine drinks or foods, in which caffeine is added for its physiological effects, must be labelled with the statement high caffeine content and not recommended for children, pregnant or breastfeeding women, followed by a reference to the caffeine content expressed in $\mathrm{mg} / 100 \mathrm{Ml}$ (47).

At national level, some EU member states have attempted to directly or de facto prohibit the marketing of EDs in their territories, or require premarket approval of key ingredients on the basis of alleged public health grounds. Hence, an Italian law prohibits the marketing of EDs, whose caffeine content exceeds $125 \mathrm{mg} / \mathrm{L}$ (46).

The market for and level of consumption of EDs are increasing every year, and while only a few have a detailed knowledge of EDs' potential harmful physiological and psychological effects, the number of publications that have documented the potential adverse risks associated with the use of these beverages remains small.

Considering the increasing prevalence of EDs in both the young and the adult population, it is of paramount importance to define the risks involved in the use and abuse of energy drinks and broaden our knowledge on their physiological and metabolic effects to avoid the consumption of these beverages to transform into an emerging public health problem. 


\section{Supplementary Material}

Supplementary material(s) is available here.

\section{Footnotes}

Authors' Contribution: The Authors have contributed equally to the work and in particular to conception, design and drafting of manuscript, Palmira Immordino and Alessandra Casuccio; to acquisition of data and literature review, Sara Palmeri, Rossella Falcone; to analysis of data, Fanny Pojero and Alessandra Casuccio.

\section{Implication for Health Policymakers, Practice, Re-} search, and Medical Education: Conflicting Interests

Funding/Support: The authors report no financial or other relationship relevant to the subject of this article.

\section{References}

1. Flotta D, Mico R, Nobile CG, Pileggi C, Bianco A, Pavia M. Consumption of energy drinks, alcohol, and alcohol-mixed energy drinks among Italian adolescents. Alcohol Clin Exp Res. 2014;38(6):1654-61. doi: 10.1111/acer.12394. [PubMed: 24717140].

2. Agriculture \& Agri-Food Canada . The energy drink segment in North America 2008. [cited 26 Sep]. Available from: http://www.ats.agr.gc. ca/us4387ehtm-2.

3. Alford C, Hamilton-Morris J, Verster JC. The effects of energy drink in combination with alcohol on performance and subjective awareness. Psychopharmacology (Berl). 2012;222(3):519-32. doi: 10.1007/s00213012-2677-1. [PubMed: 22456862].

4. Reissig CJ, Strain EC, Griffiths RR. Caffeinated energy drinks-a growing problem. Drug Alcohol Depend. 2009;99(1-3):1-10. doi: 10.1016/j.drugalcdep.2008.08.001. [PubMed: 18809264].

5. Breda JJ, Whiting SH, Encarnacao R, Norberg S, Jones R, Reinap M, et al. Energy drink consumption in europe: a review of the risks, adverse health effects, and policy options to respond. Front Public Health. 2014;2:134. doi: 10.3389/fpubh.2014.00134. [PubMed: 25360435].

6. Zucconi S, Volpato C, Adinolfi F, Gandini E, Gentile E, Loi A. Gathering consumption data on specific consumer groups of energy drinks, [190 pp.] Supporting Publications; 2013. [cited 26 Sep]. Available from: www.efsa.europa.eu/publications.

7. McCusker RR, Goldberger BA, Cone EJ. Caffeine content of energy drinks, carbonated sodas, and other beverages. J Anal Toxicol. 2006;30(2):112-4. [PubMed: 16620542].

8. Ministry of Health . National Committee for Food Safety. Opinion N. 5, 2012. Energy drinks e bevande alcoliche 2012. [cited 20 Aug]. Available from: http://www.salute.gov.it/imgs/c_17_pubblicazioni_ 1790_allegato.pdf.

9. Cappelletti S, Piacentino D, Sani G, Aromatario M. Caffeine: cognitive and physical performance enhancer or psychoactive drug? Curr Neuropharmacol. 2015;13(1):71-88. doi: 10.2174/1570159X13666141210215655. [PubMed: 26074744].

10. Rath M. Energy drinks: what is all the hype? The dangers of energy drink consumption. J Am Acad Nurse Pract. 2012;24(2):70-6. doi: 10.1111/j.1745-7599.2011.00689.x. [PubMed: 22324861].

11. U.S. Department of Health and Human Services, Food and Drug Administration, Center for Food Safety and Applied Nutrition, CFSAN Adverse Event Reporting System . Voluntary and Mandatory Reports on 5-Hour Energy, Monster Energy, and Rockstar Energy Drink. January 1, 2004, through October 23, 2012 2012. [cited 27 Jul]. Available from: http://www.fda.gov/downloads/aboutfda/centersoffices/ officeoffoods/cfsan/cfsanfoiaelectronicreadingroom/ucm 328270 . pdf.

12. U.S. Department of Health and Human Services, Food and Drug Administration, Center for Food Safety and Applied Nutrition , CFSAN Adverse Event Reporting System . Voluntary Reports on Red Bull Energy Drink. January 1, 2004, through October 23, 2012 [cited 27 Jul]. Available from: http://www.fda.gov/ downloads/AboutFDA/CentersOffices/OfficeofFoods/CFSAN/ CFSANFOIAElectronicReadingRoom/UCM328525.pdf.

13. US Food and Drug Administration . Energy drinks and supplements: investigations of adverse event reports [cited 26 Jul]. Available from: http://www.fda.gov/Food/NewsEvents/ucm328536.htm.

14. MacDonald J. The potential adverse health effects of energy drinks. Am Fam Physician. 2013;87(5):321. [PubMed: 23547548].

15. Ali F, Rehman H, Babayan Z, Stapleton D, Joshi DD. Energy drinks and their adverse health effects: A systematic review of the current evidence. Postgrad Med. 2015;127(3):308-22. doi: 10.1080/00325481.2015.1001712. [PubMed: 25560302].

16. Ferreira SE, de Mello MT, Pompeia S, de Souza-Formigoni ML. Effects of energy drink ingestion on alcohol intoxication. Alcohol Clin Exp Res. 2006;30(4):598-605. doi: 10.1111/j.1530-0277.2006.00070.x. [PubMed: 16573577].

17. Casuccio A, Bonanno V, Catalano R, Cracchiolo M, Giugno S, Sciuto $\mathrm{V}$, et al. Knowledge, Attitudes, and Practices on Energy Drink Consumption and Side Effects in a Cohort of Medical Students. J Addict Dis. 2015;34(4):274-83. doi: 10.1080/10550887.2015.1074501. [PubMed: 26466517].

18. Substance Abuse and Mental Health Services Administration, Center for Behavioral Health Statistics and Quality. The DAWN Report: Update on Emergency Department Visits Involving Energy Drinks: A Continuing Public Health Concern. Rockville, MD 2013. [cited 28 Aug]. Available from: http://archive.samhsa.gov/data/2k13/ DAWN126/sr126-energy-drinks-use.htm.

19. Oteri A, Salvo F, Caputi AP, Calapai G. Intake of energy drinks in association with alcoholic beverages in a cohort of students of the School of Medicine of the University of Messina. Alcohol Clin Exp Res. 2007;31(10):1677-80. doi: 10.1111/j.1530-0277.2007.00464.x. [PubMed: 17651468].

20. Seifert SM, Schaechter JL, Hershorin ER, Lipshultz SE. Health effects of energy drinks on children, adolescents, and young adults. Pediatrics. 2011;127(3):511-28. doi: 10.1542/peds.2009-3592. [PubMed: 21321035].

21. Martz ME, Patrick ME, Schulenberg JE. Alcohol mixed with energy drink use among u.s. 12th-grade students: prevalence, correlates, and associations with unsafe driving. J Adolesc Health. 2015;56(5):557-63. doi: 10.1016/j.jadohealth.2015.01.019. [PubMed: 25907654].

22. Reid JL, Hammond D, McCrory C, Dubin JA, Leatherdale ST. Use of caffeinated energy drinks among secondary school students in Ontario: Prevalence and correlates of using energy drinks and mixing with alcohol. Can J Public Health. 2015;106(3):e101-8. doi: 10.17269/cjph.106.4684. [PubMed: 26125234].

23. Grosso G, Pajak A, Mistretta A, Marventano S, Raciti T, Buscemi S, et al. Protective role of the Mediterranean diet on several cardiovascular risk factors: evidence from Sicily, southern Italy. Nutr Metab Cardiovasc Dis. 2014;24(4):370-7. doi: 10.1016/j.numecd.2013.09.020. [PubMed: 24370449].

24. Grosso G, Marventano S, Buscemi S, Scuderi A, Matalone M, Platania A, et al. Factors associated with adherence to the Mediterranean diet among adolescents living in Sicily, Southern Italy. Nutrients. 2013;5(12):4908-23. doi: 10.3390/nu5124908. [PubMed: 24304608].

25. Reid SD, Ramsarran J, Brathwaite R, Lyman S, Baker A, Cornish DC, et al. Energy drink usage among university students in a Caribbean country: Patterns of use and adverse effects. J Epidemiol Glob Health. 2015;5(2):103-16. doi: 10.1016/j.jegh.2014.05.004. [PubMed: 25922319]. 
26. Patrick ME, Macuada C, Maggs JL. Who uses alcohol mixed with energy drinks? Characteristics of college student users. J Am Coll Health. 2016;64(1):74-9. doi:10.1080/07448481.2015.1042877. [PubMed: 26010549].

27. Pennay A, Cheetham A, Droste N, Miller P, Lloyd B, Pennay D, et al. An Examination of the Prevalence, Consumer Profiles, and Patterns of Energy Drink Use, With and Without Alcohol, in Australia. Alcohol Clin Exp Res. 2015;39(8):1485-92. doi: 10.1111/acer.12764. [PubMed: 26061635].

28. Berger LK, Fendrich M, Chen HY, Arria AM, Cisler RA. Sociodemographic correlates of energy drink consumption with and without alcohol: results of a community survey. Addict Behav. 2011;36(5):516-9. doi:10.1016/j.addbeh.2010.12.027. [PubMed: 21276661].

29. Pomeranz JL, Munsell CR, Harris JL. Energy drinks: an emerging public health hazard for youth. JPublic Health Policy. 2013;34(2):254-71. doi: 10.1057/jphp.2013.6. [PubMed: 23486464].

30. Grosso G, Marventano S, Giorgianni G, Raciti T, Galvano F, Mistretta A. Mediterranean diet adherence rates in Sicily, southern Italy. Pub lic Health Nutr. 2014;17(9):2001-9. doi: 10.1017/S1368980013002188. [PubMed: 23941897].

31. Malinauskas BM, Aeby VG, Overton RF, Carpenter-Aeby T, BarberHeidal K. A survey of energy drink consumption patterns among college students. Nutr J. 2007;6:35. doi: 10.1186/1475-2891-6-35. [PubMed: 17974021].

32. Woolsey C, Waigandt A, Beck NC. Athletes and energy drinks: Reported risk-taking and consequences from the combined use of alcohol and energy drinks. J Appl Sport Psychol. 2010;22(1):65-71. doi: $10.1080 / 10413200903403224$.

33. Patrick ME, Maggs JL. Energy drinks and alcohol: links to alcohol behaviors and consequences across 56 days. J Adolesc Health. 2014;54(4):454-9. doi: 10.1016/j.jadohealth.2013.09.013. [PubMed: 24309196].

34. Arria AM, O'Brien MC. The "high" risk of energy drinks. JAMA. 2011;305(6):600-1. doi:10.1001/jama.2011.109. [PubMed: 21266673].

35. O'Brien MC, McCoy TP, Rhodes SD, Wagoner A, Wolfson M. Caffeinated cocktails: energy drink consumption, high-risk drinking, and alcohol-related consequences among college students. Acad Emerg Med. 2008;15(5):453-60. doi: 10.1111/j.1553-2712.2008.00085.x. [PubMed: 18439201].

36. Marczinski CA, Fillmore MT, Bardgett ME, Howard MA. Effects of energy drinks mixed with alcohol on behavioral control: risks for college students consuming trendy cocktails. Alcohol Clin Exp Res. 2011;35(7):1282-92. doi: 10.1111/j.1530-0277.2011.01464.x. [PubMed: 21676002].

37. Peacock A, Bruno R, Martin FH. Patterns of use and motivations for consuming alcohol mixed with energy drinks. Psychol Addict Behav. 2013;27(1):202-6. doi: 10.1037/a0029985. [PubMed: 22985055].

38. Smith A. Effects of caffeine on human behavior. Food Chem Toxicol. 2002;40(9):1243-55. doi: 10.1016/S0278-6915(02)00096-0. [PubMed: 12204388].

39. Giles GE, Mahoney CR, Brunye TT, Gardony AL, Taylor HA, Kanarek RB. Differential cognitive effects of energy drink ingredients: caffeine, taurine, and glucose. Pharmacol Biochem Behav. 2012;102(4):569-77. doi: 10.1016/j.pbb.2012.07.004. [PubMed: 22819803].

40. Arria AM, Caldeira KM, Kasperski SJ, Vincent KB, Griffiths RR, O'Grady KE. Energy drink consumption and increased risk for alcohol dependence. Alcohol Clin Exp Res. 2011;35(2):365-75. doi: 10.1111/j.15300277.2010.01352.x. [PubMed: 21073486].

41. Brache K, Stockwell T. Drinking patterns and risk behaviors associated with combined alcohol and energy drink consumption in college drinkers. Addict Behav. 2011;36(12):1133-40. doi: 10.1016/j.addbeh.2011.07.003. [PubMed: 21840130].

42. Guilbeau JR. Health risks of energy drinks: what nurses and consumers need to know. Nurs Womens Health. 2012;16(5):423-8. doi: 10.1111/j.1751-486X.2012.01766.x. [PubMed: 23067287].

43. Slade T, Kaye S. First Steps in Estimating Population Prevalence of Combined Alcohol and Energy Drink Use. Alcohol Clin Exp Res. 2015;39(8):1328-9. doi: 10.1111/acer.12798. [PubMed: 26147284].

44. Woolsey CL, Williams RJ, Housman JM, Barry AE, Jacobson BH, Evans MJ. Combined Use of Alcohol and Energy Drinks Increases Participation in High-Risk Drinking and Driving Behaviors Among College Students. J Stud Alcohol Drugs. 2015;76(4):615-9. [PubMed: 26098038].

45. Miller KE. Energy drinks, race, and problem behaviors among college students. J Adolesc Health. 2008;43(5):490-7. doi: 10.1016/j.jadohealth.2008.03.003. [PubMed: 18848678].

46. Cheeseman M, Simpson C, Fitzsimmons M. United Kingdom: Regulation of Energy Drinks in Europe-Toward a Stricter Regime? NABCA Daily News Update (8/12/14) 2014. [cited 27Jul]. Available from: http: //www.nabca.org/assets/docs/DNU_AUG12.pdf.

47. Regulation (EU) No 1169/2011 of the European Parliament and of the Council of 25 October 2011 2011. [cited 27 Jul]. Available from: http: //eur-lex.europa.eu/legal-content/EN/TXT/PDF/?uri=CELEX: 32011R1169\&from $=\mathrm{EN}$ 